\title{
Material Identification Code
}

National Cancer Institute

\section{Source}

National Cancer Institute. Material Identification Code. NCI Thesaurus. Code C158311.

A distinctive alpha-numeric identification code assigned by the manufacturer or distributor to a specific quantity of manufactured material or product. This may include batch number, lot number, spore lot number, batch/lot number, etc. 